(2) Open Access Full Text Article

\title{
Association between leptin gene rs7799039 polymorphism and lipid profile changes induced by isotretinoin treatment in acne patients
}

This article was published in the following Dove Press journal:

Therapeutics and Clinical Risk Management

\author{
Omar F Khabour ${ }^{1,2}$ \\ Karem H Alzoubi ${ }^{3}$ \\ Abdul Samad Firoz ${ }^{1,4}$ \\ Rafat MM Al-Awad ${ }^{2}$ \\ 'Department of Clinical Laboratory \\ Sciences, College of Applied Medical \\ Sciences, Taibah University, Madinah, \\ Saudi Arabia; ${ }^{2}$ Department of \\ Medical Laboratory Sciences, Jordan \\ University of Science and Technology, \\ Irbid, Jordan; ${ }^{3}$ Department of Clinical \\ Pharmacy, Jordan University of \\ Science and Technology, Irbid, Jordan; \\ ${ }^{4}$ Center for Genetics and Inherited \\ Diseases, Faculty of Medicine, Tabiah \\ University, Madinah, Saudi Arabia
}

Correspondence: Omar F Khabour Department of Clinical Laboratory Sciences, College of Applied Medical Sciences, Taibah University, Prince Naif bin Abdulaziz Road, Madinah 4I54I, Saudi Arabia

Email ofkhabour@taibahu.edu.sa
Introduction: Isotretinoin, a vitamin A-derived medication, is one of the effective treatments for severe acne. However, in a fraction of patients, this treatment causes significant adverse effects. Leptin is a pro-inflammatory cytokine that plays a role in apoptosis of adipose cells and sebaceous lipid metabolism. Thus, genetic polymorphisms in the leptin (LEP) gene may modulate the response to isotretinoin therapy. Here, we explore the contribution of rs 7799039 polymorphism of the $L E P$ gene in the adverse effects of the oral isotretinoin therapy among acne patients.

Materials and methods: Clinical parameters were obtained from 200 patients before and after isotretinoin treatment for acne. In addition, circulatory lipid profile and aspartate transaminase (AST) and alanine aminotransferase (ALT) enzymes from acne subjects before and 1 month after oral isotretinoin treatment were also measured.

Results: An association between the rs7799039 polymorphism and the following lipid parameters: high-density lipoprotein (HDL) at baseline and after treatment, HDL \% change, low-density lipoprotein \% change and total cholesterol \% change $(P<0.05)$. In addition, there was an association between the $L E P$ polymorphism and higher AST and ALT at baseline and after treatment $(P<0.05)$.

Conclusion: In conclusion, rs7799039 LEP polymorphism might modulate lipid parameters and liver enzymes, but not other major side effects of oral isotretinoin therapy.

Keywords: leptin, isotretinoin, acne, polymorphism, side effects

\section{Introduction}

Acne vulgaris is a prevalent inflammatory disease of the human sebaceous follicle that affects the young patients. ${ }^{1,2}$ It has an estimated prevalence of $70 \%-90 \%$, and severe acne can affect up to $12 \%$ of the adolescent population. ${ }^{3,4}$ Acne greatly impacts the quality of life of severely affected individuals as it has been shown to be associated with lesions that mostly occur on the face with the potential for permanent scarring. ${ }^{5}$

The most potent treatment of acne includes the use of isotretinoin. ${ }^{6}$ Typically, 1-2 months of isotretinoin therapy is required for an effect to be observable. ${ }^{7}$ Isotretinoin achieves its efficacy by interfering with several cellular processes such as division, growth, survival, differentiation and apoptosis. ${ }^{8}$ Among the suggested antiacne effects of isotretinoin are substantial decrease in sebum production, reduction of comedogenesis and suppression of inflammation. ${ }^{9,10}$ However, isotretinoin therapy is associated with many side effects that may limit its usage. The major adverse event of isotretinoin is teratogenicity. ${ }^{11}$ Other adverse effects include skeletal and mucocutaneous changes where isotretinoin causes myalgia, arthralgia, skin and nostrils dehydration, 
leading to nose bleeding and cracked lips. ${ }^{12}$ Other less common side effects include headache, fatigue and hair loss. ${ }^{13}$ It also causes psychiatric adverse effects, including mood swings, depression, psychosis, aggressiveness and tendency to commit suicide. ${ }^{14}$ It was also found that isotretinoin has a negative impact on lipid profile and liver function. ${ }^{6,15}$ The side effects of isotretinoin therapy vary among individuals, and their possible modulation by genetic background in patient samples still needs investigation. ${ }^{16}$

It is known that one of the mechanisms by which isotretinoin exerts its activity is by increasing the leptin levels during and after therapy. ${ }^{17}$ Leptin, which is encoded by $L E P$ gene, ${ }^{18}$ is an important adipokine that plays important roles in appetite pathway ${ }^{19}$ and energy expenditure via the regulation of lipid and sugar metabolism. ${ }^{20,21}$ Literature also showed that leptin protein is elevated during skin diseases, which suggests a role for leptin in immune network and body defenses. ${ }^{22,23}$ Thus, collectively previous data suggest a possible role for leptin in mediating some of the effects of isotretinoin.

Among LEP gene polymorphisms is rs7799039. The clinical significance of this polymorphism is well documented as it was associated with higher risk of several diseases including malnutrition inflammation syndrome, ${ }^{24}$ obesity $^{25}$ and metabolic syndrome. ${ }^{26}$ In addition, rs 7799039 was associated with blood lipid levels among Southern Chilean population, ${ }^{27}$ dyslipidemia in patients using atypical antipsychotic agents and lipid profile modulation induced by soluble fiber intake. ${ }^{28,29}$ In the current study, we examined the impact of leptin gene polymorphism (rs7799039) on lipid profile alterations as adverse effects of isotretinoin in acne patients.

\section{Materials and methods}

\section{Study subjects}

This was a cross-sectional study that was conducted at Dermatology Clinic of the Health Center at Jordan University of Science and Technology, King Abdullah University Hospital and Prince Hamazh Hospital in Jordan. The study was approved by the Institutional Review Board and University Research Committee. New acne patients who received oral isotretinoin treatment were recruited after obtaining written informed consent from participants/guardian. The inclusion criteria were new patients who were given oral isotretinoin therapy (40 mg/day) for at least 30 days. Lipid profile and aspartate transaminase (AST) and alanine aminotransferase (ALT) enzymes were assessed at baseline (before treatment) and at 30 days of treatment. Patients with liver or renal diseases, history of active neoplasm, recent major surgical operations, alcohol abuse or receiving treatment other than isotretinoin were excluded from the study. ${ }^{30}$

\section{Data collection}

Clinical data were collected from clinical case files and by interviewing the patients. The collected data included patient age, sex, body mass index, alcohol and supplement use, tobacco use and health conditions. Body mass index (BMI) was calculated based on height and weight as previously described. ${ }^{31}$

\section{Blood sampling}

Blood samples were drawn from subjects after fasting for 14 hours. To extract the DNA, $3 \mathrm{~mL}$ of blood was collected in EDTA tubes from each patient. For the analysis of biochemical markers, another $3 \mathrm{~mL}$ of blood was withdrawn in coagulant-free sterile tubes. Serum was immediately collected after coagulation by centrifugation and stored at $-80^{\circ}$ until used..$^{32}$

\section{Lipid profile and liver function tests}

The blood lipid profile that included total cholesterol (TC), high-density lipoprotein (HDL) and low-density lipoprotein (LDL) was analyzed using clinical chemistry analyzers from Roche Diagnostics International Ltd (Indianapolis, IN, USA). In addition, ALT and AST liver enzyme levels were measured using the same analyzer.

\section{DNA extraction}

DNA was extracted from whole blood using a commercially available kit as indicated by supplemented manual (ZymoResearch DNA purification system; Irvine, CA, USA). Isolated DNA was stored in TE buffer in the freezer $\left(-20^{\circ} \mathrm{C}\right)$ until used in the genotyping analysis.

\section{Genotyping analysis}

Genotyping of the rs7799039 LEP gene polymorphism was performed by the polymerase chain reaction-restriction fragment length polymorphism (PCR-RFLP) using a Promega master mix (Madison, WI, USA) and C1000TM thermos cycler (Bio-Rad Laboratories, Inc, Hercules, CA, USA). In each PCR reaction, about $50 \mathrm{ng}$ of DNA and $100 \mathrm{nM}$ of each primer were used. Primer sequences were as follows: forward: 5'TTTCCTGTAATTTTCCCGTGA3' and reverse: 5'AAAGCAAAGACAGGCATAAAA3'. PCR conditions were 5 minutes at $96^{\circ} \mathrm{C}$ followed by 34 cycles: $96^{\circ} \mathrm{C}$ for 30 seconds, $52^{\circ} \mathrm{C}$ for 45 seconds and $72^{\circ} \mathrm{C}$ for 45 seconds. The PCR reaction was terminated by 5 minutes at $72^{\circ} \mathrm{C}$. 
The amplified fragment (242 bp) was restricted with HhaI enzyme (Fermentas Canada). Restriction conditions and visualization of DNA fragments were as previously described. ${ }^{32}$

\section{Statistical analysis}

Data were analyzed using SPSS statistical software version 23 (SPSS, Inc, IL, Chicago, USA). Continuous variables were compared using unpaired $t$-test or ANOVA tests. Discrete variables were analyzed using the $\chi^{2}$ test. The significance threshold was set at a $P$-value of $<0.05$.

\section{Results}

Initially, 240 patients were invited to participate in the study, of which 220 gave consent with a response rate of $91.6 \%$. Twenty participants were excluded from the study because of missing data. Therefore, 200 patients were finally included in the study. Table 1 shows participants' demographics and their clinical measures. Most of the participants were young adults with a mean age of 23.36 years and a mean BMI of $24.07 \mathrm{~kg} / \mathrm{m}^{2}$; the majority of them were female $(79.5 \%)$.

There was a significant increase in the lipid profile (LDL, TC, triglyceride [TG]) and liver enzymes (AST, ALT) after the initiation of the oral isotretinoin therapy when compared to the baseline $(P<0.05)$. However, the levels of HDL were significantly decreased after therapy $(P<0.05)$. The concentrations of lipids and liver enzymes measured before and after 30 days of isotretinoin therapy are given in Table 2.

The results showed that rs7799039 polymorphism was associated with some lipid parameters and liver enzymes (Table 3). The CC genotype of the rs 7799039 was associated with lower HDL at baseline and after treatment $(P<0.05)$ and lower HDL \% change $(P<0.05)$. The same genotype

Table I Characteristics of acne patients of the current study $(n=200)$

\begin{tabular}{ll}
\hline Variable & Patients, $\mathbf{n} \%$ \\
\hline Age (years; mean $\pm \mathrm{SD})$ & $23.36 \pm 6.449$ \\
Body mass index $\left(\mathrm{kg} / \mathrm{m}^{2} ;\right.$ mean $\left.\pm \mathrm{SD}\right)$ & $24.07 \pm 3.802$ \\
Sex (male: female) & $20.5: 79.5$ \\
Marital status, $\mathrm{n}(\%)$ & \\
$\quad$ Single & $158(79.0)$ \\
Married & $42(21.0)$ \\
Smoking & \\
$\quad$ No & $179(89.5)$ \\
Yes & $21(10.5)$ \\
Most reported side effects, $\mathrm{n}(\%)$ & \\
Arthralgia/myalgia & $155(77.5)$ \\
Nosebleed & $159(79.5)$ \\
Headache & $\mid 49(74.5)$ \\
\hline
\end{tabular}

Table 2 Modulation of lipid profile and liver enzymes by isotretinoin therapy $(n=200)$

\begin{tabular}{|c|c|c|c|}
\hline Parameter & Measure & $\begin{array}{l}\text { Before } \\
\text { isotretinoin } \\
\text { therapy }\end{array}$ & $\begin{array}{l}\text { After } \\
\text { isotretinoin } \\
\text { therapy }\end{array}$ \\
\hline Lipid profile & HDL & $\mathrm{I} .4 \mathrm{I} \pm 0.24$ & $1.32 \pm 0.32 *$ \\
\hline \multirow[t]{3}{*}{$(\mathrm{mmol} / \mathrm{L})$} & LDL & $2.33 \pm 0.71$ & $2.78 \pm 0.76 *$ \\
\hline & TC & $4.141 \pm 0.88$ & $4.61 \pm 0.97^{*}$ \\
\hline & TG & $0.99 \pm 0.57$ & $1.32 \pm 0.77^{*}$ \\
\hline Liver function & AST & $|8.6| \pm 4.97$ & $21.71 \pm 9.84 *$ \\
\hline enzymes (U/L) & ALT & $|5.7| \pm 9.0 \mid$ & $17.73 \pm 12.30 *$ \\
\hline
\end{tabular}

Notes: Data expressed as mean \pm standard deviation. *Significant difference $(P<0.01)$.

Abbreviations: AST, aspartate aminotransferase; ALT, alanine aminotransferase; HDL, high-density lipoprotein; LDL, low-density lipoprotein; TC, total cholesterol; TG, triglyceride.

was associated with lower LDL \% change $(P<0.05)$ and TC \% change $(P<0.05)$. For liver enzymes, the AC genotype of the rs7799039 was associated with higher ALT and AST at the baseline and after treatment $(P<0.05)$.

Table 3 The impact of rs7799039 genotypes on biochemical parameters that are modulated by isotretinoin $(n=200)$

\begin{tabular}{|c|c|c|c|}
\hline \multirow[t]{2}{*}{ Parameter } & \multicolumn{3}{|c|}{ Genotypes (mean \pm SD) } \\
\hline & $\mathrm{CC}$ & AC & AA \\
\hline \multicolumn{4}{|l|}{$\mathrm{HDL}(\mathrm{mmol} / \mathrm{L})$} \\
\hline Baseline & $1.30 \pm 0.29 *$ & $1.4 \pm 0.27$ & $\mathrm{I} .37 \pm 0.3 \mathrm{I}$ \\
\hline After treatment & $1.26 \pm 0.3 I^{*}$ & $1.36 \pm 0.28$ & $1.33 \pm 0.29$ \\
\hline$\%$ change & $-9.54 \pm 1.58^{*}$ & $-3.03 \pm 1.77^{\$}$ & $-9.54 \pm 1.20$ \\
\hline \multicolumn{4}{|l|}{ LDL (mmol/L) } \\
\hline Baseline & $2.37 \pm 0.61$ & $2.30 \pm 0.82$ & $2.30 \pm 0.62$ \\
\hline After treatment & $2.81 \pm 0.70$ & $2.80 \pm 0.88$ & $2.69 \pm 0.55$ \\
\hline$\%$ change & $1.95 \pm 2.08^{\#}$ & $2.73 \pm 2.11$ & $2.02 \pm 1.96$ \\
\hline \multicolumn{4}{|l|}{$\mathrm{TC}(\mathrm{mmol} / \mathrm{L})$} \\
\hline Baseline & $4.02 \pm 0.85$ & $4.24 \pm 0.98$ & $4.10 \pm 0.70$ \\
\hline After treatment & $4.55 \pm 0.97$ & $4.67 \pm 1.09$ & $4.59 \pm 0.63$ \\
\hline$\%$ change & $1.03 \pm 1.29 \$$ & $1.44 \pm 1.42$ & $9.92 \pm 1.25$ \\
\hline \multicolumn{4}{|l|}{ TG (mmol/L) } \\
\hline Baseline & $0.97 \pm 0.55$ & $1.04 \pm 0.65$ & $0.91 \pm 0.40$ \\
\hline After treatment & $1.22 \pm 0.71$ & $1.45 \pm 0.89$ & $1.21 \pm 0.50$ \\
\hline$\%$ change & $45.5 \pm 116.9$ & $40.6 \pm 56.7$ & $29.4 \pm 44.4$ \\
\hline \multicolumn{4}{|l|}{ AST (U/L) } \\
\hline Baseline & $18.40 \pm 4.12$ & $19.46 \pm 6.04^{\epsilon}$ & $17.00 \pm 2.73$ \\
\hline After treatment & $20.61 \pm 6.05$ & $23.40 \pm 10.0^{ \pm}$ & $19.72 \pm 4.75$ \\
\hline$\%$ change & $1.956 \pm 3.70$ & $1.88 \pm 2.52$ & $1.28 \pm 3.72$ \\
\hline \multicolumn{4}{|l|}{ ALT (U/L) } \\
\hline Baseline & $15.56 \pm 10.34$ & $17.12 \pm 9.35^{t}$ & $12.68 \pm 3.26$ \\
\hline After treatment & $16.9 \pm 9.15$ & $19.44 \pm 9.85^{t}$ & $15.14 \pm 5.55$ \\
\hline$\%$ change & $|7.4| \pm 43.67$ & $23.81 \pm 50.69$ & $14.07 \pm 69.84$ \\
\hline
\end{tabular}

Notes: ${ }^{*} \mathrm{CC}$ genotype is significantly different from AC genotype. ${ }^{\$} \mathrm{~A}$ significant difference of CC genotype with AC genotype. ${ }^{*} A$ significant difference of CC with other genotypes. ${ }^{\sharp} A$ significant difference of $A C$ genotype with other genotypes.

Abbreviations: AST, aspartate aminotransferase; ALT, alanine aminotransferase; HDL, high-density lipoprotein; LDL, low-density lipoprotein; TC, total cholesterol; TG, triglyceride. 


\section{Discussion}

In this study, the roles of the rs7799039 LEP gene polymorphism and how it might modulate isotretinoin response in acne patients were explored. The results showed an association between rs 7799039 and lipid parameters such as HDL at baseline and after treatment, HDL \% change, LDL \% change and TC $\%$ change in isotretinoin-treated acne patients. In addition, there was an association between $L E P$ polymorphism and higher AST and ALT at baseline and after treatment.

Previous literature has shown an altered lipid composition and an increase in the excretion of sebum by sebaceous glands during the development of acne ${ }^{10}$ and skin inflammation. ${ }^{33}$ Leptin is known as a pro-inflammatory player in sebaceous glands since sebocytes respond to leptin stimulation with pro-inflammatory changes leading to subsequent increases in the level of inflammatory markers including cytokines. ${ }^{34}$ In addition, a previous investigation has shown that retinoids modulate the expression of leptin in adipocytes. . $^{35,36}$

The present results showed elevations of TC, TG, AST and ALT levels and decreases in HDL level in acne patients treated with isotretinoin. Such changes have been reported in previous investigations and pointed to increasing risks of cardiovascular complications, hyperlipidemia and the metabolic disorders of isotretinoin therapy. ${ }^{36,37}$

The results showed an association between the rs 7799039 CC genotype and lower HDL at baseline, lower HDL \% change, lower LDL \% change and lower TC \% change after acne treatment. Thus, the rs7799039 polymorphism of $L E P$ gene may be related to lipid profile before and during isotretinoin treatment. The impact of polymorphisms in LEP gene and leptin receptor on lipid profile has been shown by previous studies. ${ }^{38-41}$ In addition, polymorphisms in LEP gene have been shown to modulate the responses to therapeutic agents. For example, a study that was conducted on diabetic patients who were on atorvastatin showed that individuals with GG or GA genotype of $L E P 2548$ had significantly higher levels of LDL compared to AA genotype of $L E P 2548$ after treatment. ${ }^{31}$ Similarly, LEP 2548 polymorphism has been shown to modulate lipid profile in obese adult population. ${ }^{40}$ These findings are in the same line with the present results that rs 7799039 polymorphism of $L E P$ gene might affect the lipid profile in acne patients treated with isotretinoin. The mechanisms by which rs 7799039 polymorphism modulates isotretinoin lipid profile side effects require further investigations. However, rs7799039 was associated with changes in leptin level..$^{38,42}$ For example, a study that was conducted on overweight and obese children showed significantly higher leptin levels in rs7799039 AA genotype compared with other genotypes. ${ }^{38}$ In addition, AA genotype was associated with higher risk of malnutrition inflammation syndrome, ${ }^{24}$ obesity ${ }^{25}$ and metabolic syndrome. ${ }^{26}$ On the other hand, the $\mathrm{CC}$ genotype has been shown to be associated with dyslipidemia in patients using atypical antipsychotic agents. ${ }^{29}$ Finally, rs 7799039 is known to impact body weight,,$^{27,43}$ susceptibility to diseases ${ }^{26,44-46}$ and response to treatments. ${ }^{47}$

For liver enzymes, the AC genotype of the rs 7799039 was associated with higher ALT and AST at baseline and after treatment. As the impact of isotretinoin on liver function is well documented, ${ }^{6,9,12,48}$ the current findings suggest a role for the rs 7799039 polymorphism in modulating liver functions induced by isotretinoin treatment. The rs 7799039 polymorphism was associated with hepatocellular carcinoma. ${ }^{44}$ Similarly, an association between polymorphisms in the leptin receptor gene and hepatocellular carcinoma has been documented. ${ }^{49}$ The role of genes involved in the leptin pathway in modulating liver functions requires further investigations.

The abovementioned findings are a first step toward further investigations of the long-term lipid complications of isotretinoin therapy and how such complication might be modulated by genetic variations among patients. ${ }^{36,50,51}$ The link between isotretinoin therapy complications and genetic background of patients might improve the management of short-term and long-term side effects of isotretinoin use.

Among the limitations of the present study is that it did not cover all common polymorphisms of LEP gene and their relationships with isotretinoin treatment. In addition, other cytokines such as adiponectin might also modulate response and side effects of isotretinoin. Therefore, future studies could confirm present findings in other populations or on other $L E P$ polymorphisms. Furthermore, the effect of multiple dosing levels or total cumulative dose of isotretinoin per month and variation in BMI over treatment period would also be the future directions for this line of research.

\section{Conclusion}

In conclusion, rs7799039 LEP polymorphism might modulate lipid parameters, but not major side effects of oral isotretinoin therapy.

\section{Acknowledgment}

The authors would like to thank Taibah University for supporting the current investigation.

\section{Disclosure}

The authors report no conflicts of interest in this work. 


\section{References}

1. Melnik BC. Acne vulgaris: the metabolic syndrome of the pilosebaceous follicle. Clin Dermatol. 2018;36(1):29-40.

2. Stein Gold L, Baldwin HE, Lin T. Management of severe acne vulgaris with topical therapy. J Drugs Dermatol. 2017;16(11):1134-1138.

3. Rocha MA, Bagatin E. Skin barrier and microbiome in acne. Arch Dermatol Res. 2018;310(3):181-185.

4. Sutaria AH, Schlessinger J. Acne, vulgaris. In: StatPearls. Treasure Island, FL: StatPearls Publishing; 2017.

5. Gieler U, Gieler T, Kupfer JP. Acne and quality of life - impact and management. J Eur Acad Dermatol Venereol. 2015;29(Suppl 4):12-14.

6. DeKlotz CMC, Roby KD, Friedlander SF. Dietary supplements, isotretinoin, and liver toxicity in adolescents: a retrospective case series. Pediatrics. 2017;140(4). pii: e20152940.

7. Khalil S, Bardawil T, Stephan C, et al. Retinoids: a journey from the molecular structures and mechanisms of action to clinical uses in dermatology and adverse effects. J Dermatol Treat. 2017;28(8):684-696.

8. Webster GF. Isotretinoin: mechanism of action and patient selection. Semin Cutan Med Surg. 2015;34(5 Suppl):S86-S88.

9. Vallerand IA, Lewinson RT, Farris MS, et al. Efficacy and adverse events of oral isotretinoin for acne: a systematic review. Br J Dermatol. 2018;178(1):76-85.

10. Zouboulis CC, Picardo M, Ju Q, et al. Beyond acne: current aspects of sebaceous gland biology and function. Rev Endocr Metab Disord. 2016;17(3):319-334.

11. Holst H, Muhari-Stark E, Lava SA. Teratogenicity of systemic isotretinoin. Minerva Pediatr. 2018;70(1):107-109.

12. Ahmad HM. Analysis of clinical efficacy, side effects, and laboratory changes among patients with acne vulgaris receiving single versus twice daily dose of oral isotretinoin. Dermatol Ther. 2015;28(3):151-157.

13. Mobacken H, Sundstrom A, Vahlquist A. [30 years with isotretinoin. "Miracle medicine" against acne with many side effects]. Lakartidningen. 2014;111(3-4):93-96. Swedish [with English abstract].

14. Hull PR, Demkiw-Bartel C. Isotretinoin use in acne: prospective evaluation of adverse events. J Cutan Med Surg. 2000;4(2):66-70.

15. De Marchi MA, Maranhao RC, Brandizzi LI, Souza DR. Effects of isotretinoin on the metabolism of triglyceride-rich lipoproteins and on the lipid profile in patients with acne. Arch Dermatol Res. 2006;297(9): 403-408

16. Lee YH, Scharnitz TP, Muscat J, Chen A, Gupta-Elera G, Kirby JS. Laboratory monitoring during isotretinoin therapy for acne: a systematic review and meta-analysis. JAMA Dermatol. 2016;152(1):35-44.

17. Cemil BC, Ayvaz HH, Ozturk G, et al. Effects of isotretinoin on body mass index, serum adiponectin, leptin, and ghrelin levels in acne vulgaris patients. Postepy Dermatol Alergol. 2016;33(4):294-299.

18. Zhang Y, Proenca R, Maffei M, Barone M, Leopold L, Friedman JM. Positional cloning of the mouse obese gene and its human homologue. Nature. 1994;372(6505):425-432.

19. Morton GJ, Schwartz MW. Leptin and the central nervous system control of glucose metabolism. Physiol Rev. 2011;91(2):389-411.

20. Dieguez C, Vazquez MJ, Romero A, Lopez M, Nogueiras R. Hypothalamic control of lipid metabolism: focus on leptin, ghrelin and melanocortins. Neuroendocrinology. 2011;94(1):1-11.

21. Hynes GR, Jones PJ. Leptin and its role in lipid metabolism. Curr Opin Lipidol. 2001;12(3):321-327.

22. Perez-Perez A, Vilarino-Garcia T, Fernandez-Riejos P, Martin-Gonzalez J, Segura-Egea JJ, Sanchez-Margalet V. Role of leptin as a link between metabolism and the immune system. Cytokine Growth Factor Rev. 2017;35:71-84.

23. Procaccini C, La Rocca C, Carbone F, De Rosa V, Galgani M, Matarese G. Leptin as immune mediator: interaction between neuroendocrine and immune system. Dev Comp Immunol. 2017;66:120-129.

24. Sharma R, Agrawal S, Saxena A, Pandey M, Sharma RK. Association of genetic variants of ghrelin, leptin and UCP2 with malnutrition inflammation syndrome and survival in end-stage renal disease patients. Genes Nutr. 2013;8(6):611-621.
25. Zayani N, Omezzine A, Boumaiza I, et al. Association of ADIPOQ, leptin, LEPR, and resistin polymorphisms with obesity parameters in Hammam Sousse Sahloul Heart Study. J Clin Lab Anal. 2017;31(6).

26. Alnory A, Gad H, Hegazy G, Shaker O. The association of vaspin rs2236242 and leptin rs7799039 polymorphism with metabolic syndrome in Egyptian women. Turk J Med Sci. 2016;46(5):1335-1340.

27. Manriquez V, Aviles J, Salazar L, et al. Polymorphisms in genes involved in the leptin-melanocortin pathway are associated with obesityrelated cardiometabolic alterations in a southern Chilean population. Mol Diagn Ther. 2018;22(1):101-113.

28. Crescenti A, Sola R, Valls RM, Anguera A, Arola L. Polymorphisms in LEP and NPY genes modify the response to soluble fibre Plantago ovata husk intake on cardiovascular risk biomarkers. Genes Nutr. 2013;8(1):127-136.

29. Gregoor JG, van der Weide J, Loovers HM, van Megen HJ, Egberts TC, Heerdink ER. Association between LEP and LEPR gene polymorphisms and dyslipidemia in patients using atypical antipsychotic medication. Psychiatr Genet. 2010;20(6):311-316.

30. Alzoubi KH, Khabour OF, Hassan RE, Qarqaz F, Al-Azzam S, Mhaidat N. The effect of genetic polymorphisms of RARA gene on the adverse effects profile of isotretinoin-treated acne patients. Int J Clin Pharmacol Ther. 2013;51(8):631-640.

31. Al-Azzam SI, Khabour OF, Alzoubi KH, Mukattash TL, Ghanma M, Saleh $\mathrm{H}$. The role of adiponectin gene variants in glycemic control in patients with Type 2 diabetes. Endocr Res. 2014;39(1):13-17.

32. Khabour OF, Mesmar FS, Alatoum MA, Gharaibeh MY, Alzoubi KH. Associations of polymorphisms in adiponectin and leptin genes with men's longevity. Aging Male. 2010;13(3):188-193.

33. Ottaviani M, Camera E, Picardo M. Lipid mediators in acne. Mediators Inflamm. 2010;2010. pii: 858176.

34. Torocsik D, Kovacs D, Camera E, et al. Leptin promotes a proinflammatory lipid profile and induces inflammatory pathways in human SZ95 sebocytes. Br J Dermatol. 2014;171(6):1326-1335.

35. Bonet ML, Ribot J, Felipe F, Palou A. Vitamin A and the regulation of fat reserves. Cell Mol Life Sci. 2003;60(7):1311-1321.

36. Bonet ML, Ribot J, Palou A. Lipid metabolism in mammalian tissues and its control by retinoic acid. Biochim Biophys Acta. 2012;1821(1): 177-189.

37. Laker MF, Green C, Bhuiyan AK, Shuster S. Isotretinoin and serum lipids: studies on fatty acid, apolipoprotein and intermediary metabolism. Br J Dermatol. 1987;117(2):203-206.

38. Eldosouky MK, Abdu Allah AM, AbdElmoneim A, Al-Ahmadi NS. Correlation between serum leptin and its gene expression to the anthropometric measures in overweight and obese children. Cell Mol Biol (Noisy-le-grand). 2018;64(1):84-90.

39. Ferreira-Julio MA, Pinhel MS, Quinhoneiro DC, et al. LEP -2548G>a polymorphism of the leptin gene and its influence on the lipid profile in obese individuals. J Nutrigenet Nutrigenomics. 2014;7(4-6): 225-231.

40. Shabana, Hasnain S. Leptin promoter variant G2548A is associated with serum leptin and HDL-C levels in a case control observational study in association with obesity in a Pakistani cohort. J Biosci. 2016; 41(2):251-255.

41. Shabana NA, Hasnain S. Association of the leptin receptor Gln223 Arg polymorphism with lipid profile in obese Pakistani subjects. Nutrition. 2015;31(9):1136-1140.

42. Marcello MA, Calixto AR, de Almeida JF, et al. Polymorphism in LEP and LEPR may modify leptin levels and represent risk factors for thyroid cancer. Int J Endocrinol. 2015;2015:173218.

43. Martins MC, Trujillo J, Farias DR, Kac G. Polymorphisms in the leptin (rs7799039) gene are associated with an increased risk of excessive gestational weight gain but not with leptin concentration during pregnancy. Nutr Res. 2017;47:53-62.

44. Amer T, El-Baz R, Mokhtar AR, El-Shaer S, Elshazli R, Settin A. Genetic polymorphisms of IL-23R (rs7517847) and LEP (rs7799039) among Egyptian patients with hepatocellular carcinoma. Arch Physiol Biochem. 2017;123(5):279-285. 
45. Luan H, Zhang H, Li Y, et al. Association of two obesity-related gene polymorphisms LEPG2548A rs7799039 and LEPRQ223R rs1137101 with the risk of breast cancer. Oncotarget. 2017;8(35):59333-59344.

46. Qiu H, Lin X, Tang W, et al. Investigation of TCF7L2, LEP and LEPR polymorphisms with esophageal squamous cell carcinomas. Oncotarget. 2017;8(65):109107-109119.

47. Mendez-Hernandez A, Gallegos-Arreola MP, Moreno-Macias H, Espinosa Fematt J, Perez-Morales R. LEP rs7799039, LEPR rs1137101, and ADIPOQ rs2241766 and 1501299 polymorphisms are associated with obesity and chemotherapy response in Mexican women with breast cancer. Clin Breast Cancer. 2017;17(6):453-462.

48. Kizilyel O, Metin MS, Elmas OF, Cayir Y, Aktas A. Effects of oral isotretinoin on lipids and liver enzymes in acne patients. Cutis. 2014; 94(5):234-238.
49. Li Z, Yuan W, Ning S, Li J, Zhai W, Zhang S. Role of leptin receptor (LEPR) gene polymorphisms and haplotypes in susceptibility to hepatocellular carcinoma in subjects with chronic hepatitis B virus infection. Mol Diagn Ther. 2012;16(6):383-388.

50. Mantel-Teeuwisse AK, Kloosterman JM, Maitland-van der Zee AH, Klungel OH, Porsius AJ, de Boer A. Drug-Induced lipid changes: a review of the unintended effects of some commonly used drugs on serum lipid levels. Drug Saf. 2001;24(6):443-456.

51. Sinclair W. The rational use of systemic isotretinoin: a call for moderation. S Afr Med J. 2012;102(5):282-284.

\section{Publish your work in this journal}

Therapeutics and Clinical Risk Management is an international, peerreviewed journal of clinical therapeutics and risk management, focusing on concise rapid reporting of clinical studies in all therapeutic areas outcomes, safety, and programs for the effective, safe, and sustained use of medicines. This journal is indexed on PubMed Central, CAS,
EMBase, Scopus and the Elsevier Bibliographic databases. The manuscript management system is completely online and includes a very quick and fair peer-review system, which is all easy to use. Visit http://www.dovepress.com/testimonials.php to read real quotes from published authors.

Submit your manuscript here: http://www.dovepress.com/therapeutics-and-clinical-risk-management-journal 